\title{
Physiological Impacts of Fruit Ripening and Storage Conditions on Aroma Volatile Formation in Apple and Strawberry Fruit: A Review
}

\author{
Fritz K. Bangerth ${ }^{1}$ \\ Department of Special Crop Cultivation and Crop Physiology, University of \\ Hohenheim, 70599 Stuttgart, Germany
}

Jun Song Agriculture and Agri-Food Canada, 32 Main Street, Kentville, Nova Scotia, B4N $1 J 5$ Canada

\author{
Josef Streif \\ Kompetenzzentrum Obstbau-Bodensee, 88213 Ravensburg, Germany
}

Additional index words. ATP, ethylene perception, fatty acid precursors, respiration

\begin{abstract}
After a brief description of the "history of research" of aroma volatiles of apple and strawberry fruit, possible reasons for the reduced production of these important quality attributes by particular pre- and postharvest procedures are given. Among the possible physiological factors in association with reduced aroma volatile production, a reduced ethylene sensitivity, a decline in the rate of respiration as well as the content of adenine nucleotides and limited free fatty acids as precursors for aroma volatiles biosynthesis are proposed. A hypothesis about how this sequence of events leads to reduced volatile production is given and finally some suggestions of how to improve volatile synthesis are discussed.
\end{abstract}

Aroma volatiles are an important attribute of flavor in almost all tree fruit. Their significance was recognized by fruit physiologists quite early (Power and Chestnut, 1920), but wholesale and retail personal and even horticulturists have only recently discovered volatiles and aroma as important quality indices to satisfy consumers' demands and/or promote sales. As a result, more pressure is now put on fruit producers and suppliers to improve aroma volatile production in fresh-marketed as well as stored fruit. As mentioned, it was the physiologists and biochemists who were first interested in aroma volatiles, but they were more concerned about the composition and chemical structure of these compounds rather than their impact on fruit flavor and perception by the consumer. Despite the early work in the $1920 \mathrm{~s}$, significant progress was only made after the invention of gas chromatography (GC) in the second half of the last century. It was the more physiologically oriented working groups such as Drawert's in Germany

Received for publication 3 Aug. 2011. Accepted for publication 2 Nov. 2011.

We are grateful to the following colleagues and coworkers who contributed over the years to the results and conclusions: A. Brackmann; S.-J. Choi; A. Saquet; T. Tan; and H. Xuan; we also thank Dr. C. Forney at AAFC, Canada, and Roy McCormick at Kompetenzzentrum Bavendorf, Germany, for their critical reading of the manuscript.

${ }^{1}$ To whom reprint requests should be addressed; e-mail fkbang@uni-hohenheim.de.
(Drawert, 1975; Drawert et al., 1968) and Paillard's in France (Paillard, 1979) who achieved real progress concerning the chemical composition and the biosynthetic pathways of aroma volatiles. Since then, it has been established that the metabolism of fatty acids and branched amino acids may serve as precursors for the biosynthesis of aroma volatiles in fruit (Fellman et al., 2000). With the help of GC and combined GC/mass spectroscopy, the list of identified aroma volatile compounds grew rapidly to several hundred. Furthermore, the establishment of "olfactory thresholds" provided the opportunity to categorize these compounds according to their organoleptic importance. This reduced the number of compounds that were considered important organoleptically, but it raised the demands for high-resolution and sensitive instrumentation because the olfactory thresholds and production rates of some of these compounds appeared to be very low. For apples, more than 300 volatile compounds have been identified, but only 30-40 compounds are considered as flavor impact compounds (Cunningham et al., 1986). Fortunately, at least with apples, the impact of various pre- and postharvest treatments on the production rates of most of these volatile compounds is affected to a similar degree, and this allows judgments to be made without analyzing precisely each single small peak. This chemical behavior suggests that many volatile compounds are derived from similar biochemical pathways. There are exceptions to this general behavior, e.g., Brackmann et al. (1993) showed that branched and unbranched ester production in ultralow oxygen (ULO) stored apple were differentially affected by different $\mathrm{CO}_{2}$ partial pressures in the storage atmosphere. Provided with this knowledge and experimental methodologies, it was then possible to investigate further the effects of production, storage, and handling procedures on volatile aroma production in various fruit.

\section{Volatile Production Impairment by Ripening Inhibition and Storage Handlings}

Apple. Patterson et al. (1974) were among the first investigators to use the mentioned sophisticated GC methods to determine the negative influence of controlled atmosphere (CA) storage on aroma volatile production. They realized that volatile aroma production recovered nicely after regular air (RA) storage but was considerably repressed after "prolonged" CA storage, although fruit firmness was preserved much better compared with fruit stored in RA. At that time, it was known that CA reduced not only aroma volatile production, but also poststorage fruit respiration and it was speculated by Anderson and Penney (1973) and Hatfield and Patterson (1975) that reduced respiration might be one reason for the depressed volatile production. In more detailed studies conducted by Bangerth and Streif (1987), Shatat et al. (1978), and Streif and Bangerth (1988), apples were held either in low-pressure storage (LPS), or CA with $\mathrm{O}_{2}$ partial pressures ranging from 1 to $21 \mathrm{kPa}$ in combination with 0.8 to $9 \mathrm{kPa} \mathrm{CO}_{2}$ and different ethylene concentrations. These experiments showed a progressive decrease in respiration when CA conditions became more efficient in maintaining firmness and skin color and had a greater effect on reducing volatile formation than on other quality attributes. In addition, it became evident that the depression in respiration and volatile production after prolonged storage could not be overcome by addition of ethylene either applied directly into the storage container or by ethylene treatment during shelf life (Bangerth, 1984; Brackmann et al., 1993, 1995; Shatat et al., 1978). The most severe reduction in volatile production was observed with LPS at a partial $\mathrm{O}_{2}$ pressure of $1.4 \mathrm{kPa}$, which almost completely eliminated volatile emanation during as well as after LPS, whereas other quality parameters were maintained (Fig. 1; Bangerth, 1984). However, most surprisingly when aminoethoxyvinyl-glycine (AVG), an efficient inhibitor of ethylene biosynthesis, was sprayed two to three times preharvest, a similar effect in depressing volatile synthesis was observed, although these fruit were stored at ambient oxygen conditions (Bangerth et al., 1998; HalderDoll and Bangerth, 1987). Thus, low oxygen could not be the only factor repressing volatiles during storage. These early investigations into the effect of AVG were, to our knowledge, the first demonstration of a close correlation between fatty acid (FA) concentration of fruit and volatile production measured simultaneously in these fruit (Halder-Doll and 
Bangerth, 1987). There was now good evidence that long term CA and LPS storage as well as AVG treatments all repressed respiration, and research suggested that reduced volatile production may be related to a decrease in FA concentration in the fruit.

Not only postharvest but also preharvest treatments can have significant impacts on aroma formation in fresh-marketed as well as in stored fruit. Song and Bangerth (1996) showed the earlier apples are harvested, the poorer their ability to produce volatiles and again this was coupled with lower respiration and depressed FA concentrations compared with later harvested fruit (Song and Bangerth, 2003). This effect of fruit ripening on volatile production seems to be related to ethylene sensitivity because their treatment with high concentrations of ethylene stimulates fruit respiration and FA and volatile production, although to different degrees and therefore deviates in some respects from long-term stored fruit where the addition of ethylene has little to no effect (Song, 1994; Fig. 2). Fruit tend to be harvested early (i.e., pre-climacteric) for better marketing and storage behavior. However, the optimal storage behavior of preclimacteric harvested fruit does not apply to aroma production. As shown by Brackmann et al. (1993), the better firmness, sugar:acid ratio, background color, shelf life, etc., is at the expense of volatile aroma production, which is considerably reduced with earlyharvested fruit. These residual effects of premature or early harvested fruit on volatiles are still evident even after 9 or more months of ULO storage (Brackmann et al., 1993; Fellman et al., 2003). Furthermore, depending on the gas composition of the CA storage, either branched-chain (at high $\mathrm{CO}_{2}$ ) or straightchain (at low $\mathrm{O}_{2}$ ) aroma compounds are more reduced.

As discussed, preharvest as well as postharvest factors and procedures can reduce aroma volatiles with a similar reduction in consumer perception (Hoehn et al., 2008). The following discussion emphasizes postharvest behavior of aroma volatiles. We followed the volatile production of apples during and after storage under LPS or ULO or treatment with AVG- and 1-methylcyclopropene (1-MCP). All of these treatments reduced volatile production, particularly after an extended storage period. Full or partial recovery is possible during shelf life after $\approx 4$ to 5 months of storage; however, thereafter, this is increasingly difficult to achieve. As mentioned, low $\mathrm{O}_{2}$ cannot be the main or exclusive factor influencing volatile biosynthesis, because extensive treatments with AVG or 1-MCP followed by RA storage (Halder-Doll and Bangerth, 1987; Fig. 9) have similar inhibitive effects. The alternative possibility that volatile deficiency is in some way related at least in a climacteric fruit like apple to the physiology and particularly the sensitivity of the fruit to ethylene seems to be reasonable. This conclusion was based on the fact that when high ethylene concentrations were added to apples in an LPS storage container, a declining response of the fruit to ethylene measured in terms of firmness loss

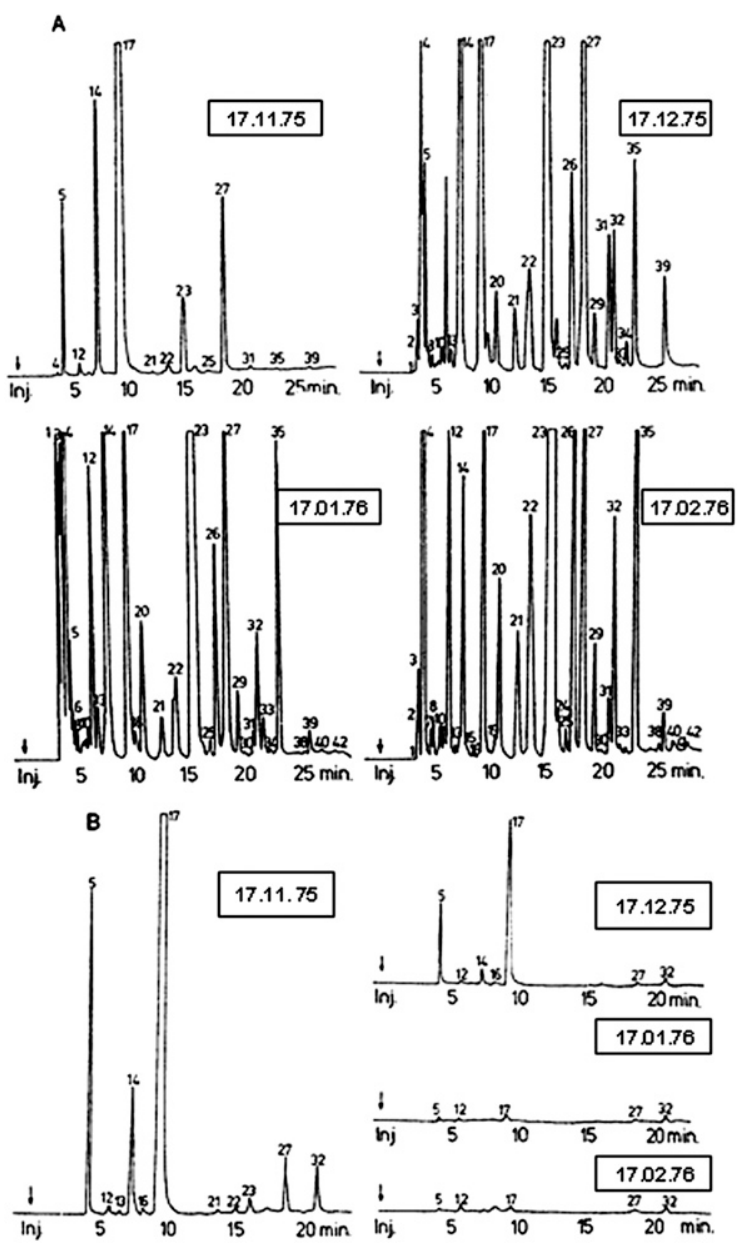

Fig. 1. Aroma volatile production of 'Golden Delicious' apple fruit during a 4 months storage period. (A) Regular air storage $\left(\mathrm{Co}\right.$.) at $1{ }^{\circ} \mathrm{C}$; (B) low-pressure storage (LPS) at 50 Torr $(\approx 6.6 \mathrm{kPa})$ pressure corresponding to $1.4 \mathrm{kPaO}_{2}$ and at a temperature of $1{ }^{\circ} \mathrm{C}$. Each single chromatogram depicts the aroma volatile production of $20 \mathrm{~kg}$ of fruit during a 1-month storage period (modified after Shatat et al., 1978).

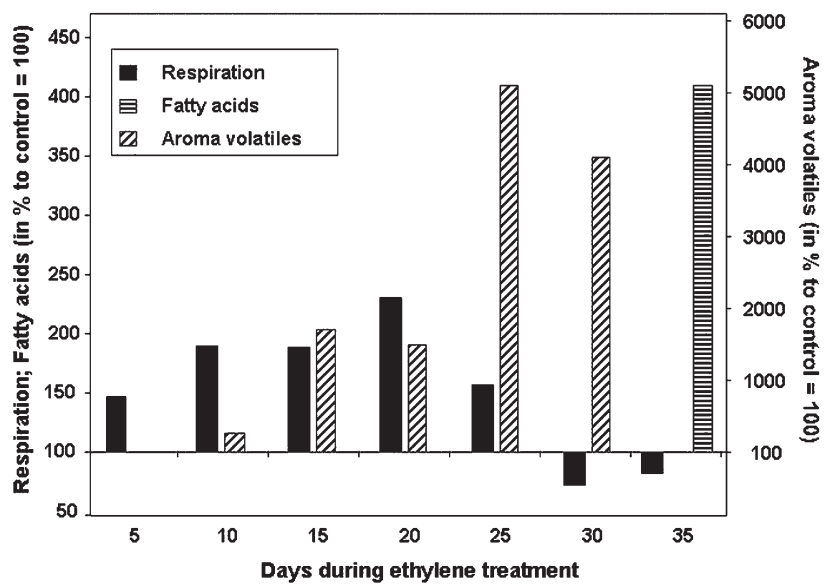

Fig. 2. Continuous treatment of immaturely harvested 'Golden Delicious' fruit with $100 \mu \mathrm{L} \cdot \mathrm{L}^{-1}$ ethylene and its effect on respiration, fatty acids, and aroma volatiles. Total fatty acids were measured only once $35 \mathrm{~d}$ after fruits were harvested and exceeded control (control $=100$ ) values by 50 times (modified after Song and Bangerth, 1996, 2003; Tan, 1999).

or increase in respiration and volatile production was observed (Bangerth, 1984; Bangerth et al., 1998). A decline in sensitivity to exogenous ethylene was also observed by Cook et al. (1985) who discovered this effect after treating carnation petals with AVG. Alternatively, investigations into substrate availability, $\mathrm{O}_{2}$ concentration, temperature, and a few other possibilities were also performed with apple fruit but no conclusive evidence could be found that these factors by themselves played a decisive role in ethylene sensitivity or volatile 
formation. This was the case during storage as well as during shelf life at ambient temperature and $\mathrm{O}_{2}$ concentrations and at saturating ethylene levels $\left(100 \mu \mathrm{L} \times \mathrm{L}^{-1}\right.$ or greater $)$. Preliminary experiments with apple, banana, and tomato fruit showed that whenever ethylene was held below its particular physiological threshold value for an extended period, ethylene perception/action seemed to be impaired and unable to recover. Autocatalytic ethylene production on the other hand was marginally affected, although this by itself depends on ethylene and suggests different receptors for ethylene are present in fruit, which was confirmed later (see subsequently). This conclusion was based on fruit firmness, respiration, ethylene, and volatile production measurements.

With current molecular techniques or "labeled MCP," it should now be possible to better prove/disprove this "ethylene insensitivity hypothesis." In Arabidopsis and tomatoes, a family of ethylene receptor isoforms has been identified and cloned (Giovannoni, 2007; O'Malley et al., 2005). It therefore seems conceivable that particular ethylene receptor family members are responsible for particular signaling pathways (Giovannoni, 2007). The signaling pathway responsible for autocatalytic ethylene biosynthesis may, therefore, be differentially regulated from that for respiration and volatile biosynthesis. Provided this hypothesis is proven correct, then the question arises: What biochemical/physiological step $(s)$ are affected by this failure in ethylene sensitivity/perception? With respect to the volatiles found in climacteric apple fruit, the most related change would be a decrease in respiration, because this shows such a close relationship to ethylene perception and volatile production (see subsequently). This, in fact, was observed in pre-climacteric fruit (Song and Bangerth, 1996) as well as in fruit after prolonged LPS or ULO storage (Bangerth and Streif, 1987; Brackmann et al., 1993). In fruit harvested at a pre-climacteric stage, recovery in volatile production was possible by high ethylene treatment at harvest time, whereas after extensively long-term fruit storage, recovery in volatile production was possible only after treatment with high ethylene concentrations after a few months, but not at all after $\approx 6$ to 8 months (Fig. 2) (Brackmann et al., 1995). The detrimental effect of long-term storage on aroma volatile production was greater when more immature fruit were stored. Furthermore, one needs to question: What follows physiologically as a result of reduced respiration? One obvious result would be an insufficient supply of "high-energy" compounds like adenine and/or pyridine nucleotides and, as a possible result, lack of biosynthesis of volatile precursors such as FAs. This argument is valid only if these FA precursors are derived from de novo synthesis and are not metabolites from membrane disintegration as suggested frequently in the past (for a more detailed discussion of this subject, see Dixon and Hewett, 2000; and Song and Bangerth, 2003).
In apple, the predominate respiratory substrate is malic acid, which is oxidized by malic enzyme to pyruvate (Dilley, 1970). In comparison with the glycolytic pathway with its gain of two adenosine- $5^{\prime}$-triphosphate (ATPs) per molecule of glucose before entering the tricarboxylic acid cycle, the malic acid pathway does not produce any ATP but supplies reduced Nicotinamid adenine dinucleotide phosphate (NADPH). If glucose is totally oxidized, it can theoretically yield 38 ATPs. Judged from the increase in malic enzyme activity during the respiratory climacteric of apple and an expected corresponding decrease in glycolysis, a deficiency in ATP is conceivable, in particular under conditions of extended storage or 1-MCP treatment with their strong depressing effect on respiration (Figs. 2, 7, and 8). Unfortunately, direct feeding of ATP to fruit tissue, as has been done with FA precursors previously (Harb et al., 2000), is not feasible because ATP seems unable to cross the plasma membrane. Therefore, a direct test of an ATP deficiency theory is presently not available.

\section{Comparison of Aroma Volatile Production by Apple and Strawberry}

Studies of respiration rates, adenine and pyridine nucleotides, FAs, and volatile production in "non-climacteric strawberries" were performed and compared with previously obtained data from climacteric apples. Results from strawberry are similar to those of apple in some areas but are different in others. First of all, the respiration and ethylene production of strawberries neither confirm the classical picture of a non-climacteric fruit such as Citrus nor correspond with a climacteric fruit. Respiration in strawberry as well as ethylene production increases markedly during the course of ripening as well as during storage at ambient temperatures (Song, 1994; Tan, 1999) (Fig. 3), which suggests a more intermediate position for strawberry as also mentioned by Trainotti et al. (2005). These last authors also discuss the participation of different ethylene receptors in this context. However, whereas total ethylene production is considerably lower, respiration can be twice as high as in apple. Despite this high respiration, total volatile production in strawberry is comparable to that of apple during the postharvest period (Song, 1994). Similar to apple, strawberry shows considerably lower volatile production when immature as compared with fully ripe fruit (Fig. 4) and reduced volatile emission after prolonged storage (Tan, 1999) (last aspect not shown).

In contrast to the mentioned similarities, considerable differences between apple and strawberry are found with the concentrations of FAs and the aforementioned nucleotides. Whereas the concentration of the supposedly most important two free $\mathrm{FA}$ fractions in apple $\left(\mathrm{C}_{16: 0}\right.$ to $\left.\mathrm{C}_{18: 2}\right)$ is slightly increasing, this does not seem to be the case for all strawberry cultivars (Fig. 5) (Song, 1994; Tan, 1999) The level of free FAs, which showed the best correlation to aroma production in apples (Song and Bangerth, 2003), remained high during ripening. In contrast in strawberry, the concentration of both total and free FAs are considerably lower than in apple (note differences in graduation of scale and reference basis). The latter one for apple was per square centimeter peel and for strawberry per $1 \mathrm{~kg}$ fruit flesh and only total FAs are increasing during ripening (Fig. 5). Provided these low free FA concentrations are an indicator of reduced production of ester type volatiles as suggested for apple by Song and Bangerth (2003), this should be more valid for strawberry with its exceptionally low concentrations of this free FA fraction. Consequently, treatment of strawberries with FA precursors should increase ester volatile production markedly. This was in fact the case when "white mature" but not always "fully ripe" fruit were treated with 3 FA metabolites viz. butanal, hexanal, and heptanal (Fig. 6). FAs themselves are not useful to be fed as precursors because at higher concentration, they disturb cell membrane function and at lower concentration, they are not taken up readily. Aldehydes as natural FA metabolites (Drawert, 1975) are therefore more suitable to be applied as aroma precursors.

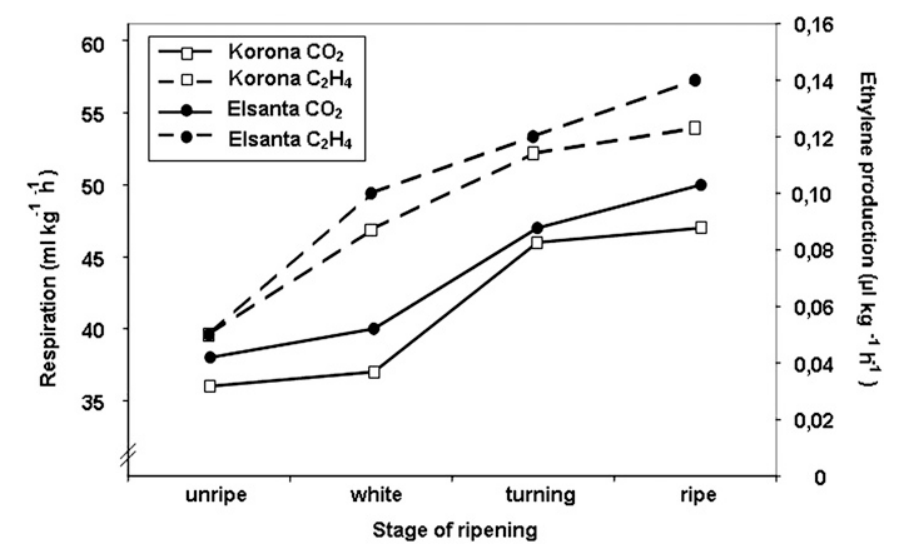

Fig. 3. $\mathrm{CO}_{2}$ and ethylene production of strawberry (cvs. Elsanta and Korona) fruit harvested at four consecutive ripening stages starting $17 \mathrm{~d}$ after flowering with: unripe: $30 \mathrm{~d}$; mature white: $20 \mathrm{~d}$; turning: $10 \mathrm{~d}$; and ripe: $0 \mathrm{~d}$, respectively, before fruit attained the full red ripe color (modified after Tan, 1999). 


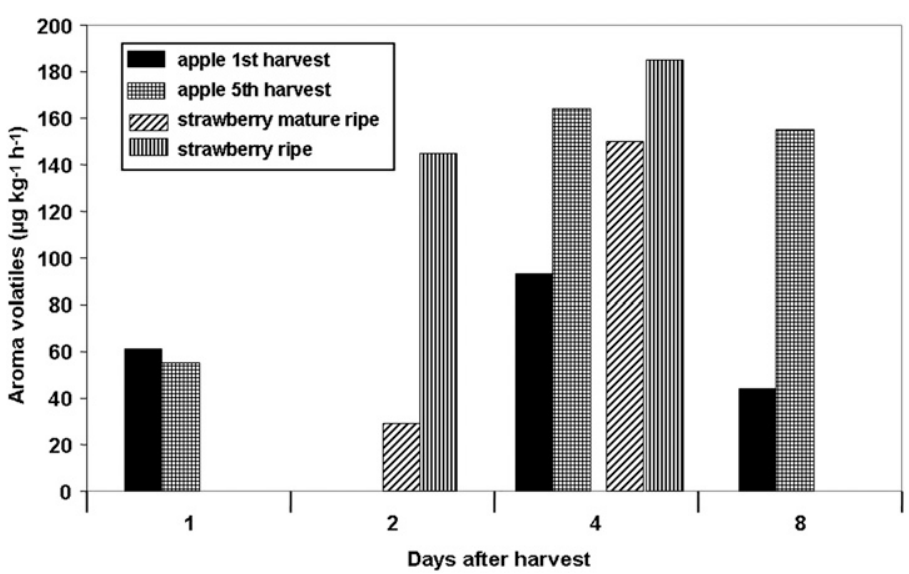

Fig. 4. Aroma volatile production of apple (cv. Golden Delicious) and strawberry (cv. Korona) fruit harvested at the immature and mature stage. Volatiles were trapped by the Tenax method in the outgoing air of the storage vessel and analyzed by gas chromatography at $20^{\circ} \mathrm{C}$. Because strawberries could only be kept for $4 \mathrm{~d}$, volatiles were measured only on Days 2 and 4 for this fruit. For apple, volatile production does not change quickly and was therefore measured only on Days 1, 4, and 8 (modified after Song, 1994; and Song and Bangerth, 2003).

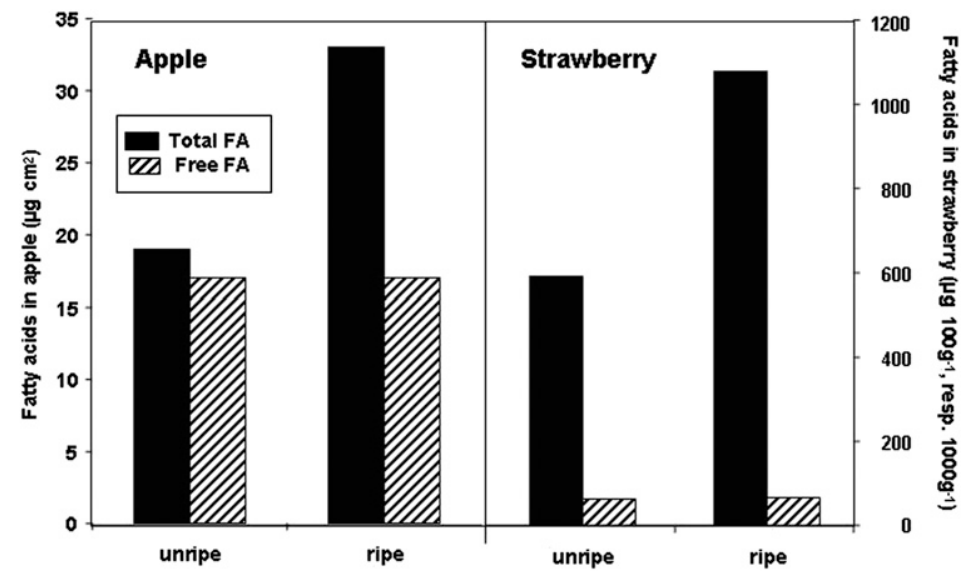

Fig. 5. Comparison between the concentrations of total and free fatty acids of apple and strawberry fruit harvested at the unripe and ripe stage. Note the differences in scales and the references on which the results are based (total fatty acids in $100 \mathrm{~g}$; free fatty acids in $1 \mathrm{~kg}$ ). A direct comparison is therefore not possible but in relative terms the differences remain similar.

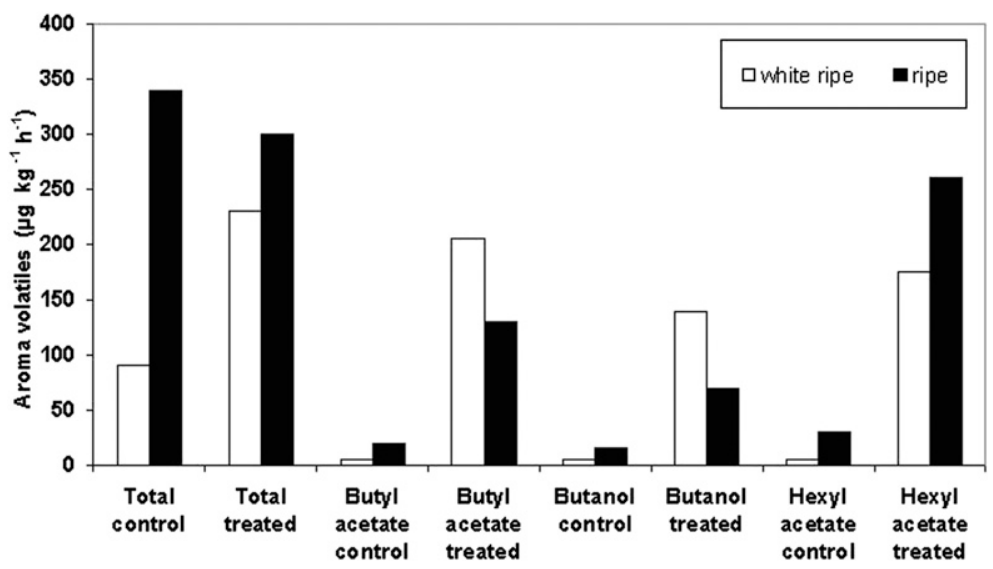

Fig. 6. Treatment of white and red ripe strawberries during shelf life with a combination of butanal, pentanal, and hexanal $\left(0.2 \mathrm{~mL} \cdot \mathrm{kg}^{-1}\right.$ each) Total volatiles and butylacetate, hexyl acetate, and butanol were measured (modified after Song, 1994).
This experiment illustrates that in strawberry similar to apple, the lack of FA as precursors for volatile production is a serious limiting factor, whereas the enzymatic machinery, needed for ester formation, seems much less restricted. However, the activity of the enzymes alcohol dehydrogenase and alcohol-acetyl CoA transferase have also been proposed as an additional limiting factor for volatile production in strawberries (Ke et al., 1994; Perez et al., 1993).

As shown, many similarities exist between climacteric apples and "non-climacteric" strawberries as far as volatile production and related precursors are concerned. Low volatile production in apple as a result of an immature harvest or prolonged storage conditions was traced back by Saquet et al. (2003) and Tan and Bangerth (2001) to impaired adenine and less so to pyridine nucleotide levels, which may limit de novo synthesis of free FA. For this reason, the same nucleotides were analyzed in strawberry. As shown in Figures 7 and 8, the level of ATP and adenosine diphosphate (ADP) considerably deviates from those in apple. ATP, one of the presumed limiting factors for volatile synthesis in apple under the mentioned conditions, changes comparatively little in strawberries during ripening as well as during storage at 25 or $8{ }^{\circ} \mathrm{C}$ (results for storage not shown). In addition, these ATP concentrations were many times higher compared with those measured in apple peel and pulp. Concentration differences between apple and strawberry in pyridine nucleotides were smaller (approximately threefold higher in strawberries) and again changed little during ripening and storage (results not shown). Because the ratio of ATP/ ADP increased only slightly (from $\approx 5.5$ to 6.5 ) during ripening as well as during storage, it seems that the high concentrations of ATP are a result of either the considerably higher respiration and/or the preferred glycolytic instead of "malic enzyme" pathway in strawberry. Considering the much higher levels of these nucleotides in strawberries and the stable ATP/ADP ratio, it is difficult to assume a limiting function for these compounds in FA as well as volatile biosynthesis in these fruit. In fact, the high adenyl nucleotide level in strawberry suggests a different regulation of volatile production with, presumably, a greater importance of NAD/NADPH. In addition, key enzymes like alcohol dehydrogenase and alcohol acyltransferase (AAT) may have a more significant function in strawberry than in apple (Aharoni et al., 2000; Defilippi et al., 2005; Ke et al., 1994; Perez et al., 1993). Although Fellman et al. (1993) detected a decline in alcohol acyltransferase (AAT) in CA-stored 'Rome' apples, neither NAD/ NADPH nor AAT are considered as limiting factors in apple (Echeverria et al., 2004; Escalada and Archbold, 2009; Lara et al., 2008). These results were also deduced indirectly by all our feeding experiments with FA precursors (results not shown). As a result of such differences in the regulation of volatile formation, different strategies may be needed when trying to improve 


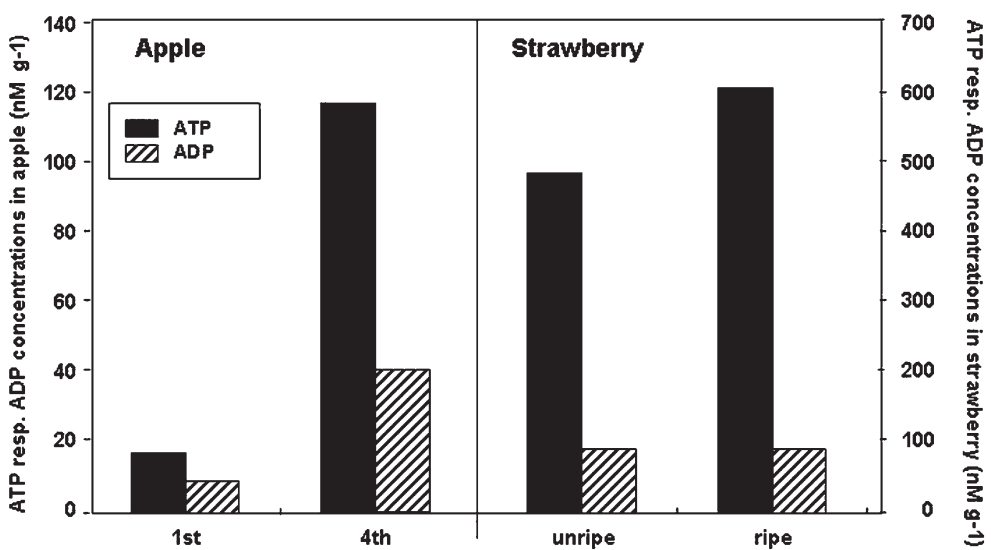

Fig. 7. Comparison between the concentrations of ATP and ADP. respectively (resp.) of apple (peel) and strawberry (whole fruit) at two different ripening stages (modified after Tan, 1999; and Tan and Bangerth, 2001). ATP = adenosine-5' -triphosphate; ADP = adenosine diphosphate.
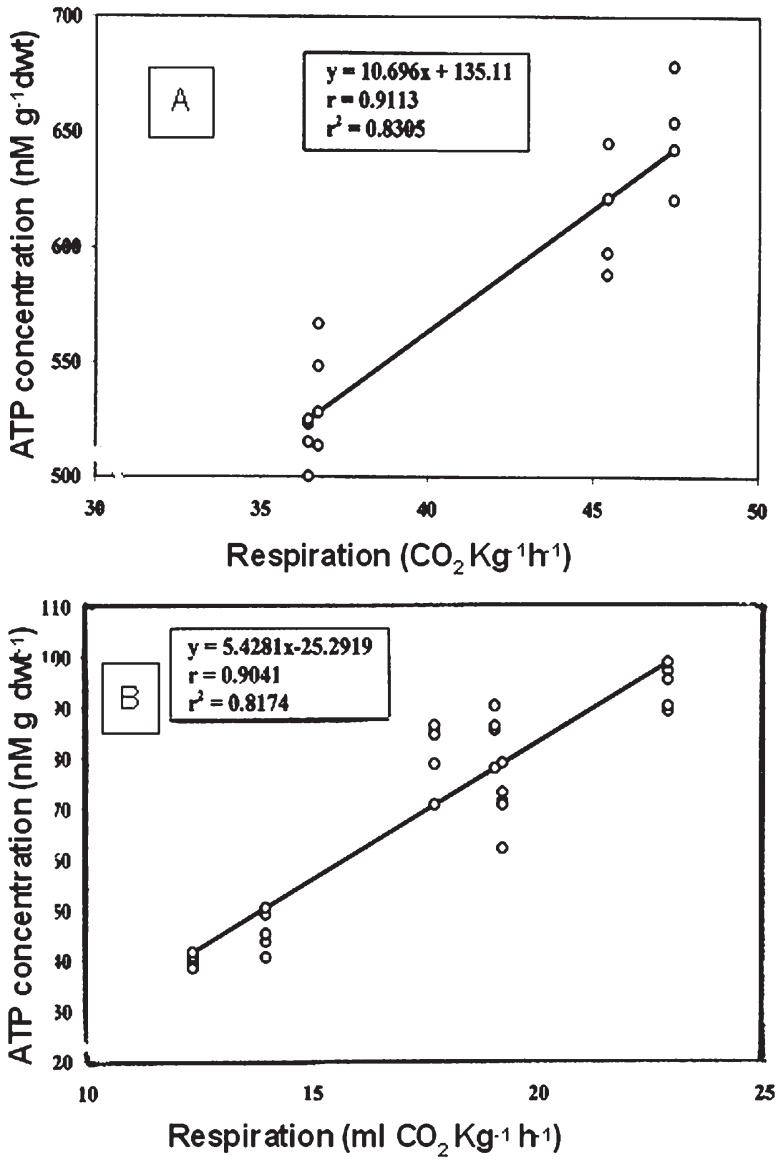

Fig. 8. Relationship between respiration and ATP concentration of strawberry (A) and apple (B). The much steeper slopes in ATP concentration of strawberries are obvious (modified after Tan, 1999). ATP = adenosine-5' -triphosphate.

volatile production in these two different fruit.

As indicated, the response of apple fruit to ethylene plays a paramount role in volatile production at harvest as well as during/after storage, which is particularly exemplified after AVG and/or 1-MCP treatments, but also after long-term ULO storage (Bangerth, 1984; Defilippi et al., 2005; Fan et al., 1998; Halder-
Doll and Bangerth, 1987; Kondo et al., 2005; Lalel et al., 2003; Streif and Bangerth, 1988; Xuan and Streif, 2005). These treatments gradually diminish ethylene responsiveness with the result of keeping volatile production at a very low level. Currently, there are few ideas about how to overcome this deficiency in apple fruit quality. Surprisingly, however, modifications of the traditional CA/ULO stor- age procedures seem to provide some perspective. "Dynamic CA storage" (this term is now used in a different sense and "interrupted CA" is used instead subsequently) as suggested by Mattheis et al. (1998) or ULO storage after a 20 -d period of RA storage (delayed ULO storage) as described by Saquet et al. (2003) both improved volatile production even after many months of CA storage. Delayed ULO showed improved volatile production concurrently with increases in respiration, ATP, and FA concentrations and thus strengthens the suggestion about such a sequence of events for apple. In addition, this increase in volatile production did not impair other quality attributes such as sugar:acidity ratio, skin color, firmness, or physiological disorders. Despite this, however, presently it is not known by which physiological mechanism(s) interrupted/delayed ULO is able to preserve ethylene perception/action and volatile production even after many months after ULO storage. Using apples expressing the antisense suppression ACO (1-Aminocyclopropane-carboxylase oxidase) gene, it was revealed that the ethylene-mediated ripening process in apple is controlled at two levels, both through the dependence for ethylene and the sensitivity to ethylene. The volatile production is highly dependent on ethylene perception but less sensitive to a low concentration of ethylene (Johnston et al., 2009).

Recently several genes in relation to ethylene perception and signal transduction have been found and characterized for several fruit such as tomato, melon, passion fruit, and apple (Dal Cin et al., 2006; Giovannoni, 2007; Wang et al., 2007). Wang et al. (2007) demonstrated that the two genes coding for ethylene response factors they discovered in apple (MdERF1 and MdERF2) are preferably (MdERF1) or exclusively (MdERF2) expressed in apple fruit and their transcription is developmentally (ripening) regulated and strongly inhibited by the application of 1-MCP. This demonstrates that transcription of these genes is regulated by ethylene making them particularly suitable for the mentioned investigations into ethylene responsiveness. More specific experiments on apple fruit ethylene receptor genes and transcription factors may be needed to answer the question whether there is loss of ethylene sensitivity after long-term permanent ULO storage and if yes, how to overcome the impaired ethylene insensitivity.

\section{Conclusion}

The mentioned publications and experiments demonstrate that particular storage procedures either prevent or reduce the ability of fruit to produce sufficient aroma volatiles. As a result, a negative residual effect of these storage procedures on volatile production was first found by Patterson et al. (1974) and by a number of additional researchers thereafter (see reviews by Dixon and Hewett, 2000; and Yahia, 1994). A plausible explanation for reduced volatile production and some other traits was later suggested (Bangerth, 1984) by assuming a reduced sensitivity of the fruit for ethylene 


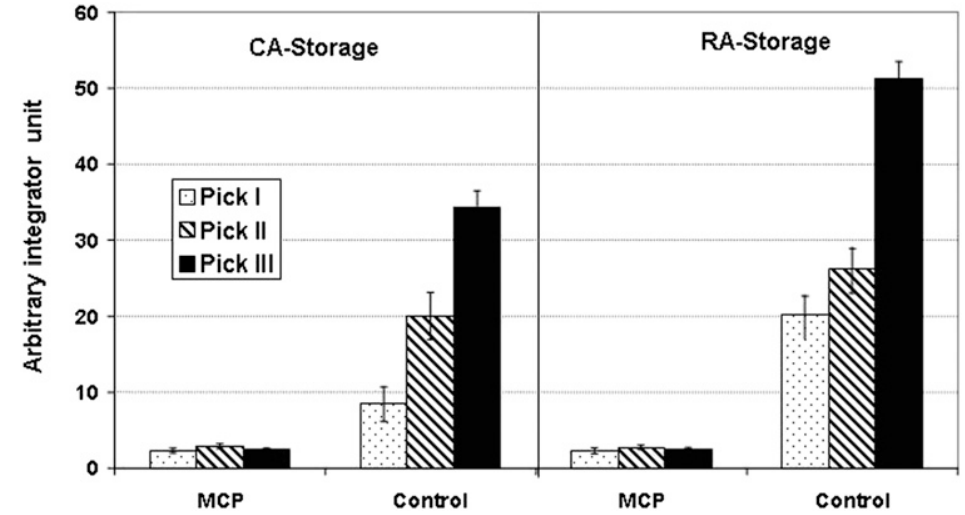

Fig. 9. Effect of a 1-MCP treatment on volatile production of 'Jonagold' apple fruit at different ripening stages (Pick I 20 d; Pick II 10 d in advance of Pick III, which was at optimal harvest). 1-MCP treatment was with $625 \mathrm{ppb}$ for $24 \mathrm{~h}$ and storage was at $1{ }^{\circ} \mathrm{C}$ and $\mathrm{RA}=$ regular atmosphere; and $3 \mathrm{kPa} \mathrm{CO}, 1 \mathrm{kPa}$ $\mathrm{O}_{2}=$ CA storage. Collection and measurement of volatiles was after $10 \mathrm{~d}$ shelf life at $20^{\circ} \mathrm{C}$ (modified after Xuan and Streif, 2005). 1-MCP = 1-methylcyclopropene; CA = controlled atmosphere.

as the first step in a cascade of events. More recent experiments using AVG and 1-MCP (Fig. 9) have resulted in more evidence for this hypothesis. Production of autocatalytic ethylene is a prerequisite for the general initiation of ripening including volatile production of climacteric fruit.

Initiation of autocatalytic ethylene, however, requires ethylene and at higher concentrations as more unripe the fruits are. This indicates that this step is also developmentally regulated (Choi et al., 1994), possibly by epigenetic factors. Immediate CA or ULO storage of pre-climacteric fruit may prevent "removal" of these epigenetic factors, which, as a result, may temporarily or permanently prevent autocatalytic ethylene and aroma volatile production.

Therefore, one could speculate that autocatalytic ethylene may operate as a switch to start developmental epigenetic processes causing histone modifications and/or DNA demethylation, which then may overcome the non-accessibility of relevant gene(s) responsible, e.g., for an increase in respiration followed by ATP production and the de novo synthesis of free FAs as the main precursors of most straight-chain aroma volatiles.

The two modifications in storage procedures described by Mattheis et al. (1998) and Saquet et al. (2003) may be useful tools to test this ethylene insensitivity hypothesis. "Delayed CA" (Saquet et al., 2003) may overcome ethylene insensitivity by starting the developmental switch, mentioned previously, while the fruit are still under ambient atmospheric cool storage conditions before storage is switched to ULO conditions, which, when operated from the beginning, may prevent this switch. Thus, after ULO storage, fruit may still maintain the ability to produce volatiles after transfer to shelf life conditions. Provided this histone/DNA-ethylene "accessibility hypothesis" described is correct, it should be possible to be tested by molecular methods combined with labeled 1-MCP. If correct, delayed CA or dynamic interrupted CA could be even more optimized for improved volatile production using molecular methods.

\section{Literature Cited}

Aharoni, A., C.P. Leopold, and H.C. Keizer. 2000 Identification of the SAAT gene involved in strawberry biogenesis by use of DNA microarrays. Plant Cell 12:647-661.

Anderson, R.E. and R.W. Penney. 1973. Quality of 'Stayman Winesap' apples stored in air, controlled atmospheres, or controlled atmospheres followed by storage in air. HortScience 8:507-508

Bangerth, F. 1984. Changes in sensitivity for ethylene during storage of apple and banana fruits under hypobaric conditions. Sci. Hort. 24:151163.

Bangerth, F. and J. Streif. 1987. Effect of aminoethoxyvinylglycine and low-pressure storage on the post-storage production of aroma volatiles by 'Golden Delicious' apples. J. Sci. Food Agr. 41:351-360.

Bangerth, F., J. Streif, J. Song, and A. Brackmann. 1998. Investigations into the physiology of volatile aroma production of apple fruits. Acta Hort. 464:189-194.

Brackmann, A., J. Streif, and F. Bangerth. 1993. Relationship between reduced aroma production and lipid metabolism of apples after longterm controlled atmosphere storage. J. Amer. Soc. Hort. Sci. 118:243-247.

Brackmann, A., J. Streif, and F. Bangerth. 1995. Einfluss von CA- bzw. ULO-Lagerbedingungen auf Fruchtqualität und Reife bei präklimakterisch und klimakterisch geernteten Äpfeln. II Auswirkung auf Ethylen-, $\mathrm{CO}_{2-}$, Aroma- und Fettsäureproduktion. Gartenbauwissenschaft 60:1-6.

Choi, S.-J., G. Bufler, and F. Bangerth. 1994. Ethylensensitivität von Apfel- und Tomatenfrüchten während ihrer Entwicklung. Gartenbauwissenschaft 59:154-158.

Cook, D., M. Rasche, and W. Eisinger. 1985. Regulation of ethylene biosynthesis and action in cut carnation flower senescence by cytokinins. J. Amer. Soc. Hort. Sci. 110:24-27.

Cunningham, D.G., T.E. Acree, J. Barnard, R.M. Butts, and P.A. Braell. 1986. Charm analysis of apple volatiles. Food Chem. 19:137-147.

Dal Cin, V., F.M. Rizzini, A. Botton, and P. Tonutti. 2006. The ethylene biosynthesis and signal transduction pathway are differently affected by 1-MCP in apple and peach fruit. Postharvest Biol. Technol. 42:125-133.

Defilippi, B.G., A. Dandekar, and A.A. Kader. 2005. Relationship of ethylene biosynthesis to volatile production, related enzyme, and precursor availability in apple peel and flesh tissues. J. Agr. Food Chem. 53:3133-3141.

Dilley, D.R. 1970. Enzymes, p. 179-204. In: Hulme, A.C. (ed.). The biochemistry of fruit and their products. Vol. 1. Academic Press, London, UK.

Dixon, J. and E.W. Hewett. 2000. Factors affecting apple aroma/flavour volatile concentration. N. Z. J. Crop Hort. Sci. 28:155-173.

Drawert, F. 1975. Formation des aromes a differents stades de l'evolution du fruit; Enzymes intervenant dans cette formation, p. 309-319. In: Ulrich, R. (ed.). Facteurs et Regulation de la Maturation de Fruits. Centre National Recherche Scientifique, Paris, France.

Drawert, F., W. Heimann, R. Emberger, and R. Tressel. 1968. Über die Biogenese von Aromastoffen bei Pflanzen und Früchten. III. Gaschromatographische Bestandsaufnahme von Apfelaromastoffen. Phytochem. 7:881883.

Echeverria, G.J., J. Garell, M.L. Lopez, and I. Lara. 2004. Volatile production, quality and aroma related enzyme activities during maturation of 'Fuji' apples. Postharvest Biol. Technol. 31: 217-227.

Escalada, V.S. and D.D. Archbold. 2009. Preharvest aminoethoxyvinylglycine plus postharvest heat treatments influence apple fruit ripening after cold storage. HortScience 44:1637-1640.

Fan, X., J.P. Mattheis, and D. Buchanan. 1998 Continuous requirement of ethylene for apple fruit volatile synthesis. J. Agr. Food Chem. 46:1959-1963.

Fellman, J.K., D.S. Mattinson, B.C. Bostick, J.P. Mattheis, and M.E. Patterson. 1993. Ester biosynthesis in 'Rome' apples subjected to low oxygen atmospheres. Postharvest Biol. Technol. 3:201-214.

Fellman, J.K., T.W. Miller, D.S. Mattinson, and J.P. Mattheis. 2000. Factors that influence biosynthesis of volatile flavor compound in apple fruits. HortScience 35:1026-1033.

Fellman, J.K., D.R. Rudell, D.S. Mattinson, and J.P. Mattheis. 2003. Relationship of harvest maturity to flavor regeneration after CA storage of Delicious apples. Postharvest Biol. Technol. 27:39-51.

Giovannoni, J.J. 2007. Fruit ripening and its manipulation, p. 278-291. In: Gan, S. (ed.). Senescence processes in plants. Blackwell Publishing, Oxford, UK

Halder-Doll, H. and F. Bangerth. 1987. Inhibition of autocatalytic $\mathrm{C}_{2} \mathrm{H}_{4}$-biosynthesis by AVGapplications and consequences on the physiological behaviour and quality of apple fruits in cool storage. Sci. Hort. 33:87-96.

Harb, J., J. Streif, and F. Bangerth. 2000. Response of controlled atmosphere (CA) stored 'Golden Delicious' apples to the treatments with alcohols and aldehydes as aroma precursors. Gartenbauwissenschaft 65:154-161.

Hatfield, S.G.S. and B.D. Patterson. 1975. Abnormal volatile production by apples during ripening after controlled atmosphere storage, $\mathrm{p}$. 57-62. In: Ullrich, R. (ed.). Facteurs et Regulation de la Maturation de Fruits. Centre National Recherche Scientifique, Paris, France.

Hoehn, E., D. Baumgartner, F. Gasser, and S. Gabioud. 2008. Ripening regulation and consumer expections. Acta Hort. 796:83-93.

Johnston, J.W., K. Gunaseelan, P. Pidakala, M. Wang, and R. Schaffer. 2009. Co-ordination of early and late ripening events in apples is regulated through differential sensitivities to ethylene. J. Expt. Bot. 60:2689-2699.

Ke, D., L. Zhon, and A.A. Kader. 1994. Mode of oxygen and carbon dioxide action on strawberry 
ester biosynthesis. J. Amer. Soc. Hort. Sci. 119: 971-975.

Kondo, S., S. Setha, D.R. Rudell, D.A. Buchanan, and J.P. Mattheis. 2005. Aroma volatile biosynthesis in apples affected by 1-MCP and methyl jasmonate. Postharvest Biol. Technol. 36:61-68.

Lalel, H.J.D., Z. Singh, and S.C. Tan. 2003. The role of ethylene in mango fruit aroma volatile biosynthesis. J. Hort. Sci. Biotechnol. 78:485-496.

Lara, I., A. Ortiz, G. Echeverria, M.L. Lopez, and J. Grall. 2008. Development of aroma-synthesising capacity throughout fruit maturation of Mondial Gala apples. J. Hort. Sci. Biotechnol. 83:253259.

Mattheis, J.P., D.A. Buchanan, and J.K. Fellman. 1998. Volatile compounds emitted by Gala apples following dynamic atmosphere storage. J. Amer. Soc. Hort. Sci. 123:426-432.

O’Malley, R.C., F.J. Rodriguez, J.J. Esch, B.M. Binder, P. O'Donnell, H.J. Klee, and A.B. Bleecker. 2005. Ethylene-binding activity, gene expression levels, and receptor system output for ethylene receptor family members from Arabidopsis and tomato. Plant J. 41:651-659.

Paillard, N. 1979. Biosynthese de produits volatils de la pomme: Formation des alcools et des esters á partir des acides gras. Phytochem. 18:1165-1171.

Patterson, B.D., S.G.S. Hatfield, and M. Knee. 1974. Residual effects of controlled atmosphere storage on the production of volatile compounds by two varieties of apples. J. Sci. Food Agr. 25:843-849.

Perez, A.G., C. Sanz, and J.M. Olias. 1993. Partial purification and some properties of alcohol acyltransferase from strawberry fruit. J. Agr. Food Chem. 41:1462-1466.

Power, F.B. and V.K. Chestnut. 1920. The odorous constituents of apples. Emanation of acetaldehyde from the ripe fruit. J. Amer. Chem. Soc. 42:1509-1526.

Saquet, A.A., J. Streif, and F. Bangerth. 2003. Impaired aroma production of CA-stored 'Jonagold' apples as affected by adenin and pyridine nucleotide levels and fatty acid concentrations. J. Hort. Sci. Biotechnol. 78:695-705.

Shatat, F., F. Bangerth, and J. Neubeller. 1978. Beeinflussung der Fruchtaromaproduktion durch drei verschiedene Lagerverfahren. Gartenbauwissenschaft 43:214-222.

Song, J. 1994. Einfluss verschiedener Erntezeitpunkte auf die Fruchtreife unter besonderer Berücksichtigung der Aromabildung bei Äpfeln, Tomaten und Erdbeeren. PhD thesis, Uni. Hohenheim, Stuttgart, Germany.

Song, J. and F. Bangerth. 1996. The effect of harvest date and aroma compound production from 'Golden Delicious' apple fruit and relationship to respiration and ethylene production. Posth. Biol. Technol. 8:259-269.

Song, J. and F. Bangerth. 2003. Fatty acids as precursors for aroma volatile biosynthesis in preclimacteric and climacteric apple fruit. Posth. Biol. Technol. 30:113-121.
Streif, J. and F. Bangerth. 1988. Production of volatile aroma substances by 'Golden Delicious' apple fruits after storage for various times in different $\mathrm{CO}_{2}$ and $\mathrm{O}_{2}$ concentrations. J. Hort. Sci. 63:193-199.

Tan, T. 1999. Stoffwechselphysiologische Untersuchungen zur Ursache der verminderten Aromabildung von früh geernteten Apfel- und Erdbeerfrüchten sowie von unter ULO-Bedingungen langzeitgelagerten Apfelfrüchten. PhD thesis, Uni. Hohenheim, Stuttgart, Germany.

Tan, T. and F. Bangerth. 2001. Are adenine and/or pyridine nucleotides involved in the volatile production of prematurely harvested or long term ULO stored apple fruits? Acta Hort. 553:215-218.

Trainotti, L., A. Pavanello, and G. Casasoro. 2005. Different ethylene receptors show an increase expression during the ripening of strawberries: Does such an increment imply a role for ethylene in the ripening of theses non-climacteric fruits? J. Expt. Bot. 56:2037-2046.

Wang, A., D. Tan, A. Takahashi, T.Z. Li, and T. Harada. 2007. MdERFs, two ethylene response factors involved in apple fruit ripening. J. Expt. Bot. 58:3743-3748

Xuan, H. and J. Streif. 2005. Effect of 1-MCP on the respiration and ethylene production as well as on the formation of aroma volatiles in 'Jonagold' apple during storage. Acta Hort. 682:1203-1210.

Yahia, E.M. 1994. Apple flavor, p. 197-234. In: Janick, J. (ed.). Hort. Reviews. Vol. 16. John Wiley \& Sons Inc., New York. 